Ege Tıp Dergisi / Ege Journal of Medicine 2020; 59 (1): 28-33

\title{
Menopoz sonrası kemik yoğunluğu ile ergenlik döneminde gerçekleşen ilk doğum arasındaki ilişkinin araştırılması
}

An investigation of the relationship between postmenopausal bone density and the first delivery in adolescence

\author{
Ayşe Şahin D \\ Duygu Ersak (D) \\ Hasan Şahin \\ Aytekin Tokmak \\ Zekai Tahir Burak Kadın Sağlığı EAH, Kadın Hastalıkları ve Doğum Kliniği, Ankara, Türkiye
}

Öz

Amaç: Illk doğum yaşının postmenopozal kemik yoğunluğu ile ilişkisini değerlendirmek.

Gereç ve Yöntem: Rutin yıllık kontrol amacıyla hastanemiz menopoz polikliniğine başvuran ve çalışma koşullarını karşılayan ardışık tüm hastalar bu çalışmaya dahil edildi. Her hastanın obstetrik öyküsü ve demografik özellikleri sorgulanarak ilk doğum yaşları kaydedildi. Vertebra ve femur kemik yoğunluğu dual enerji $x$ ışını absorpsiyometri (DEXA) cihazı ile ölçüldü.

Bulgular: Çalışmaya adölesan doğum öyküsü olan 36 , adölesan doğum öyküsü olmayan 44 olmak üzere toplamda 80 hasta dahil edildi. Gruplar arasında yaş, menopoz süresi, çocuk sayısı, aylık gelir, vücut kitle indeksi, menopoz tipi, mesleki durum, eğitim durumu, ilaç kullanımı, obezite açısından istatistiksel olarak anlamlı fark saptanmadı $(p>0,05)$. İki grup arasında ölçülen Lomber T, Lomber Z, femur T ve femur $Z$ skorları arasında istatistiksel olarak anlamlı fark saptandı $(p<0,05)$.

Sonuç: Adölesan yaşta yapılan doğumlar hem femur hem de bel kemik mineral yoğunluğunu pozitif yönde etkileyebilir.

Anahtar Sözcükler: Ergenlikte hamilelik, adölesan tıbbı, kemik yoğunluğu, absorpsiyometri, canlı doğum.

\begin{abstract}
Aim: To evaluate the relationship between postmenopausal bone density and first birth age.

Materials and Methods: All consecutive patients who were admitted to our menopausal outpatient clinic and met the study criteria were included in this study. Obstetric history and demographic characteristics of each patient were questioned, and the first birth ages were recorded. Bone density of the vertebra and femur were measured by dual energy $x$-ray absorptiometry (DEXA).
\end{abstract}

Results: $A$ total of 80 patients were included in the study, 36 with a history of adolescent birth and 44 without a history of adolescent birth. No statistically significant difference was found between the groups in terms of age, duration of menopause, number of children, monthly income, body mass index, menopause type, occupational status, educational status, drug use, and obesity ( $p>0.05$ ). There was a statistically significant difference between the two groups of lumbar $T$, lumbar $Z$, femur $T$ and femur $Z$ scores $(p<0.05)$.

Conclusion: Adolescent births may positively affect both the lomber and femur bone mineral density. Keywords: Pregnancy in adolescence, adolescent medicine, bone density, absorptiometry, live birth.

\footnotetext{
Yazışma Adresi: Aytekin Tokmak

Zekai Tahir Burak Kadın Sağığı EAH, Kadın Hastalıkları ve

Doğum Kliniği, Ankara, Türkiye

E-mail: aytekintokmak@gmail.com

Makalenin Geliş Tarihi: 20.11.2018 Kabul Tarihi: 03.04.2019
} 


\section{Giriş}

Adölesan terimi çocukluktan erişkinliğe geçişi tanımlamaktadır. Dünya Sağlık Örgütü'nün (DSÖ) tanımıyla adölesan dönem 10-19 yaşları arasındaki dönemi kapsamaktadır (1). Hem gelişmiş hem gelişmekte olan tüm dünya ülkelerinde adölesan gebelikler çok önemli bir sağlık sorunu yaratmaktadır (2). 2017 yılı istatistiklerine göre ülkemiz nüfusunun yaklaşık $\% 15,8$ 'ini adölesan yaş grubu (10-19 yaş arası) oluşturmaktadır. Adölesan doğurganlık hızı ise 2017 yılında binde 21'e düşmüştür. Diğer bir ifadeyle, 15-19 yaş grubundaki her bin kadın başına 21 doğum gerçekleşmiştir. Yine aynı yıl yapılan evilik yaşı değerlendirmesinde kadınlarda ilk evlilik yaşının ortalama 24,6'ya, ilk canlı doğum yaşının ise 26'ya yükseldiği görülmüştür. Türkiye İstatistik Kurumu tarafından yayınlanan bu resmi veriler, en son 2013 Türkiye Nüfus ve Sağlık Araştırması'nda yayınlanan verilerle kıyaslandığında ülkemizde adölesan gebeliklerin azalması bakımından yetersiz de olsa olumlu yönde bir iyileşmenin olduğunu göstermektedir $(3,4)$.

Adölesan dönemi sekonder seks karakterlerinin gelişmeye başladığı ve seksüel reprodüktif özelliğin kazanıldığı dönem olarak da bilinmektedir. Adölesan dönemdeki fizyolojik değişikliklerden birisi de kemik kitlesinde artıştır (5). Kadınlar doruk kemik kütlesine 16 ila 25 yaşlar arasında ulaşmaktadır ve bu doruk kemik kütlesi gelecek hayattaki osteoporoz gelişimi için en önemli belirteçtir (6). Daha önce yapılan çalışmalarda adölesan dönemdeki gebeliğin doruk kemik kitlesi üzerinde zararlı olabileceği ve postmenopozal dönemde osteoporozla ilişkili olabileceği gösterilmiştir $(7,8)$. Ancak bunun aksi yönünde çalışmaların da yayınlanması $(9,10)$, adölesan gebeliğin sonraki yıllardaki kemik sağlığı üzerine olan etkisini tartışmalı hale getirmiştir.

Gebelikte fizyolojik olarak artmış kemik döngüsü ve kalsiyum salınımı mevcuttur (11). Adölesan anneler hamilelik ve emzirme döneminde özellikle kalsiyum alımı düşük olduğunda geri dönüşümsüz kemik kaybı riskinde olabilirler. Ancak, kalsiyum alımı olan gebelerde bu sürecin durdurulabildiği gösterilmiştir $(12,13)$.

Kemik kütlesi ağırlıklı olarak genetik faktörler olmak üzere daha az bir oranda hormonal faktörler, fiziksel aktivite ve besinlerden etkilenmektedir (14-16). Östrojen, osteoblast aktivasyonuna ve osteoklast inhibisyonuna yol açan önemli bir osteojenik hormondur. Menopozun erken aşamasında, azalan östrojen seviyesine bağlı olarak artan osteoklastik aktivite ve azalan osteoblastik aktivite kemik kütlesinin azalmasında önemli rol oynar (17). Gebeliğin maternal kemik kütlesiyle olan ilişkisi tam olarak anlaşılamamış olsa da, menopozda izlenenin aksine gebelik sırasındaki artan osteoblastik aktiviteye bağlı kemik kütlesinde artış olduğu (5), adolesan gebeliklerin doruk kemik kitlesi üzerinde pozitif etkili olduğu düşünülebilir. Ancak, adolesan gebeliklerin kemik kütlesi ve kalitesi üzerindeki uzun dönem etkilerini değerlendiren çok az çalışma mevcuttur ve aralarındaki ilişki tam olarak aydınlatılamamıştır.

Tüm bu bilgiler ışığında çalışmamız, adölesan gebeliğin postmenopozal dönemde kemik mineral dansitesi arasındaki ilişkiyi değerlendirmek amacıyla kurgulanmıştır.

\section{Gereç ve Yöntem}

Çalışmamıza, Mart 2018- Mayıs 2018 tarihleri Zekai Tahir Burak Kadın Sağlığı Hastanesi Menopoz polikliniğine başvuran, çalışma kriterlerini karşılayan ve yaşları 49-59 arasında değişen ardışık 80 postmenopozal kadın dâhil edildi. Kronik böbrek hastalığı, kontrolsüz tiroit hastalığı, paratiroit hastalıkları, kanser, kemoterapi tedavisi almış, pelvik radyoterapi almış ve kemik kütlesini etkileyebilecek olan düzenli ilaç kullanımı (heparin, bifosfonatlar, lityum), hipertansiyon hariç sistemik hastalığı olan, primer infertilite öyküsü olan hastalar dışlama kriteri olarak kabul edildi.

Menopoz; Dünya Sağlık Örgütü'nün (DSÖ) tanımına göre ovaryum aktivitesinin yitirilmesi sonucunda menstrüasyonun kalıcı olarak sonlanması olarak kabul edildi (18). Adölesan gebelik ve doğum dönemi; ilk doğum yaşının 20 yaş altı olması olarak kabul edildi. Retrospektif klinik çalışma olarak tasarlanan bu araştırma için hastanemiz eğitim ve planlama kurulundan gerekli onay alındı. Çalışmaya dahil edilen tüm hastalardan klinik bilgilerinin hastanenin gerekli kurullarının onayı dahilinde bilimsel araştırmalarda kullanılabileceğine dair yazılı ve sözlü onam alınmıştır. Çalışmaya dahil edilen tüm postmenopozal hastalar ilk doğumunu adölesan yaşta yapanlar ( $\mathrm{n}: 36)$ ve yapmayanlar (n: 44) olarak iki grup halinde değerlendirildi.

Tüm hastalara genel fizik muayene ve pelvik muayene yapıldı. Her hastanın jinekolojik öyküsü ve demografik özellikleri sorgulandı. Hastaların yaşı, menopoz yaşı, ilk doğum yaşı, vücut kitle indeksi (VKI), obstetrik ve jinekolojik özgeçmiş bilgileri, evlilik süresi, mesleği, eğitim düzeyi, oral 
kontraseptif kullanımı, geçirilmiş operasyon öyküsü, aylık gelir düzeyi kayıt altına alındı. Hastaların boyları ve vücut ağırlıkları profesyonel olarak kalibre edilmiş cihazlar kullanılarak ölçüldü. VKI= ağırlık $(\mathrm{kg}) /$ boy uzunluğu $(\mathrm{m})^{2}$ formülü kullanılarak hesaplandı.

Vertebra ve femur kemik yoğunluğu $\left(\mathrm{g} / \mathrm{cm}^{2}\right)$, üretici tarafından sağlanan standart bir görüntüleme fantomuyla günlük olarak kalibre edilen dual enerji $x$ ışını absorpsiyometri cihazı (DEXA QDR 4500, Hologic, Discovery, ABD) ile ölçüldü. Değerlendirme deneyimli bir hekim tarafından yapıldı. Her kadın için, ayrıca femur boynu, femur total ve lomber total $\mathrm{T}$ skorları ölçüldü ve kaydedildi. Lomber vertebra 1-4 ve femur kemik mineral yoğunlukları her hasta için standart olarak sağ tarafından ölçüldü. Varyasyon katsayısı \%1 veya daha azdı.

\section{Istatistiksel analiz}

Verilerin analizinde IBM SPSS Statistics 22 programı kullanıldı. Verilerin normal dağııma uygunluğu Shapiro-Wilk testi dikkate alınarak incelenmiş olup; normal dağılıma sahip değişkenlerin analizinde parametrik yöntemler, normal dağılıma sahip olmayan değişkenlerin analizinde non-parametrik yöntemler kullanılmıştır. Bağımsız iki grubun karşılaştırılmasında Independent-Samples $T$ test ve Mann-Whitney $U$ test kullanılmıştır. Kategorik verilerin karşılaştırılması ise Chi-Square ve Fisher exact testi ile test edilmiştir. Normal dağılım gösteren nümerik değişkenler tablolarda ortalama \pm standart sapma (SS) olarak gösterilirmiştir. Kategorik veriler ise $n$ (sayı) ve yüzdelerle (\%) ifade edilmiştir. Veriler $\% 95$ güven düzeyinde incelenmiş olup $p$ değeri 0,05 ten küçük anlamlı kabul edilmiştir.

\section{Bulgular}

Çalışmaya adölesan doğum öyküsü olan 36 , adölesan doğum öyküsü olmayan 44 olmak üzere toplamda 80 hasta dahil edildi. Adölesan gebelik öyküsü olan hastaların yaş ortalaması (ortalama $\pm S S$ ) $53,9 \pm 4,7$ ve adölesan gebelik öyküsü olmayan hastaların yaş ortalaması $53,5 \pm 4,0$ yıl olup aralarında istatistiksel açıdan fark yoktu $(p>0,05)$. Ayrıca, gruplar arasında menopoz yaşı, çocuk sayısı, aylık gelir, boy, kilo, VKI, menopoz tipi, mesleki durum, eğitim durumu, ilaç kullanımı, obezite $\left(\mathrm{VKI}>30 \mathrm{~kg} / \mathrm{m}^{2}\right.$ ) açısından istatistiksel olarak anlamlı fark saptanmadı $(p>0,05)$.
Adölesan gebelik öyküsü olan hastaların ilk doğum yaşı ortalaması (ortalama $\pm S D$ ) 18,4 $\pm 1,4$ ve adölesan gebelik öyküsü olmayan hastaların ilk doğum yaş ortalaması $24,4 \pm 3,0$ yıl olup aralarında istatistiksel olarak anlamlı fark mevcuttu $(p<0,001)$. Gruplar arasında evlilik süreleri arasında da istatistiksel olarak anlamlı fark mevcuttu $(p<0,001)$ (Tablo-1).

Adölesan gebelik öyküsü olan ve olmayan hastalar arasında kemik mineral dansitometrisinde (KMD) ölçülen Lomber $T$ ve Lomber Z, düzeyleri arasında adölesan gebelik öyküsü olanlar lehine istatistiksel olarak anlamlı fark saptandı (sırasıyla $p=0,018, p=0,007$ ). Benzer şekilde, iki grup arasında KMD'de ölçülen Femur $T$ ve Femur $Z$ skorları arasında istatistiksel olarak anlamlı fark saptandı (sırasıyla $\mathrm{p}=0,031, \mathrm{p}=0,045)($ Tablo-2).

\section{Tartışma}

Adölesan gebelik öyküsünün, kemik kütlesi üzerine olan etkisi halen tartışmalı bir konudur. Çalışmamız, adölesan gebeliğin postmenopozal dönemde kemik mineral dansitesindeki yerini araştırmak ve bu tartışmalı konuya katkı sağlamak için dizayn edilmiştir.

Lloyd ve arkadaşları tarafından 2002 yayınlanan bir çalışmada, adölesan gebelik öyküsü olan hastalarda daha düşük femoral kemik mineral dansitesi skorları izlemişlerdir (5). Bu çalışmaya toplamda 16 hasta dahil edilmiş olup, çalışmamızdan farklı olarak 19-21 yaşlarında kemik ölçümleri, kardiyovasküler risk faktörleri ve endokrin profilleri karşılaştırılmıştır. Ancak, bu çalışmadaki hasta sayısının göreceli olarak düşük olması sonuçların tesadüfi olabileceğini düşündürmektedir (5).

Ward ve arkadaşları ise adölesan gebelerde radyal diafizdeki kemik kütlesinin normalden daha düşük olduğunu izlemişlerdir (19). Cho ve arkadaşları tarafından 2012 yılında yayınlanan benzer bir çalışmaya, 719 postmenopozal hasta dahil edilmiş ve adölesan gebelik öyküsü olan postmenopozal hastalarda femur boynu, femur ve lomber omurgada daha düşük kemik mineral dansitesi skorları izlenmiştir. Ancak, bu çalışmada adölesan gebelik öyküsü olan ve olmayan hastalar arasında ortalama yaş değerleri açısından istatistiksel olarak anlamlı fark mevcuttur (8). Artan yaş ile birlikte kemik mineral dansitometrinin negatif etkilendiği ve osteoporoza yatkınlık izlendiği daha önce yapılan birçok 
çalışmada izlenmiştir $(20,21)$. Bu nedenle yaşa bağlı KMD etkilenmesini önlemek ve sadece KMD etiyolojisine yönelik değerlendirme yapabilmek için olguların yaşı bakımından gruplar arasında fark olmaması gerekmektedir. Kendi çalışmamızda gruplar arasında ortalama yaş değerleri açısından istatistiksel olarak anlamlı fark bulunmamıştır.

Tablo-1. Adölesan doğum öyküsü olan ve olmayan olguların demografik özelliklerinin karşılaştırılması.

\begin{tabular}{|c|c|c|c|}
\hline & $\begin{array}{l}\text { Adölesan doğum olan } \\
\text { grup }(n: 36)\end{array}$ & $\begin{array}{l}\text { Adölesan doğum olmayan grup } \\
(\mathrm{n}: 44)\end{array}$ & P değeri \\
\hline Yaş & $53,9 \pm 4,7$ & $53,5 \pm 4,0$ & 0,660 \\
\hline Menopoz yaşı & $47,0 \pm 4,8$ & $47,6 \pm 4,0$ & 0,503 \\
\hline Çocuk sayısı & $2,4 \pm 0,8$ & $2,2 \pm 0,7$ & 0,121 \\
\hline İlk doğum yaşı & $18,4 \pm 1,4$ & $24,4 \pm 3,0$ & $<0,001$ \\
\hline Aylık gelir & $1800 \pm 720$ & $2170 \pm 1390$ & 0,392 \\
\hline Boy & $160,1 \pm 5,3$ & $158,3 \pm 5,9$ & 0,146 \\
\hline Kilo & $77,6 \pm 12,8$ & $72,3 \pm 12,6$ & 0,067 \\
\hline VKi & $30,3 \pm 5,1$ & $29,0 \pm 5,6$ & 0,272 \\
\hline Evlilik süresi & $34,4 \pm 6,4$ & $28,7 \pm 7,4$ & $<0,001$ \\
\hline Menopoz tipi & & & 1,000 \\
\hline Doğal & $34(94,4)$ & $41(93,2)$ & \\
\hline Cerrahi & $2(5,6)$ & $3(6,8)$ & \\
\hline Meslek & & & 0,235 \\
\hline Ev hanımı & $30(83,3)$ & $32(72,7)$ & \\
\hline Emekli & $2(5,6)$ & $8(18,2)$ & \\
\hline Çalışan & $4(11,1)$ & $4(9,1)$ & \\
\hline Eğitim & & & 0,079 \\
\hline Okur yazar & $4(11,1)$ & $3(6,8)$ & \\
\hline İlkokul & $25(69,4)$ & $19(43,2)$ & \\
\hline Ortaokul & $2(5,6)$ & $5(11,1)$ & \\
\hline Lise & $4(11,1)$ & $11(25)$ & \\
\hline Üniversite & $1(2,8)$ & $6(13,6)$ & \\
\hline Hipertansiyon(+) & $10(27,8)$ & $7(15,9)$ & 0,197 \\
\hline OKS (+) & $14(38,9)$ & $9(20,5)$ & 0,070 \\
\hline Obezite & $18(50)$ & $16(36,4)$ & 0,220 \\
\hline
\end{tabular}

VKi: vücut kitle indeksi, OKS: oral kontraseptif. Veriler ortalama \pm standart sapma ve sayı (yüzde) olarak gösterilmiştir. p<0,05 istatiksel olarak anlamlı kabul edilmiştir.

Tablo-2. Adölesan doğum öyküsü olan ve olmayan olguların lomber vertebra ve femur KMD değerleri.

\begin{tabular}{|c|c|c|c|}
\hline & $\begin{array}{l}\text { Adölesan doğum olan grup } \\
(n: 36)\end{array}$ & $\begin{array}{l}\text { Adölesan doğum olmayan grup } \\
(\mathrm{n}: 44)\end{array}$ & P değeri \\
\hline Lomber T & $-0,96 \pm 1,31$ & $-1,66 \pm 0,97$ & 0,018 \\
\hline Lomber Z & $0,11 \pm 1,29$ & $-0,65 \pm 0,94$ & 0,007 \\
\hline Femur T & $0,25 \pm 1,01$ & $-0,34 \pm 0,94$ & 0,031 \\
\hline Femur Z & $0,97 \pm 1,02$ & $0,35 \pm 0,92$ & 0,045 \\
\hline
\end{tabular}

KMD: kemik mineral dansitesi. Veriler ortalama \pm standart sapma olarak gösterilmiştir.

$p<0,05$ istatiksel olarak anlamlı kabul edilmiştir. 
Bu çalışmaların aksine 2018 yılında yayınlanan Teerapornpuntakit ve arkadaşları tarafından yapılan retrospektif bir çalışmada, adölesan gebelik ve emzirmenin, doruk kemik kütlesi zamanında kemik mineral dansitesini olumsuz etkilemediğini gösterdiler (9). Çalışmaya, bizimkinden farklı olarak 24-30 yaşları arasında adölesan gebelik ve emzirme öyküsü olan hastalar ve yaşları eşleştirilmiş kontroller dahil edilmiştir.

2014 yılında Yüce ve arkadaşları tarafından yayınlanan bir çalışmada, adölesan gebeliğin perimenopozal dönemdeki kemik mineral dansitesiyle ilişkisi değerlendirilmiştir. Çalışmaya, 87'si adölesan gebelik öyküsü ve 153'ü kontrol olmak üzere, 40-55 yaşları arasında perimenopozal dönemde olan toplamda 240 hasta dahil edilmiştir. Çalışmamızda olduğu gibi demografik faktörler açısından gruplar arasında belirgin farklılık bulunmamaktadır. Yazarlar adölesan gebelik öyküsü olan hastalarda perimenopozal dönemde femoral kemik mineral dansitesinin pozitif etkilendiğini iddia etmişlerdir (10).

Osteoporoz bilindiği üzere multifaktöriyel bir hastalıktır. Çalışmamız, retrospektif bir klinik çalışma olup neden sonuç ilişkisi kurabilecek bir çalışma tasarımına sahip değildir. Her iki grupta kaydedilen parametreler arasında fark olmamasına rağmen, postmenopozal KMD düzeyleri üzerine etkisi olabilecek kadının beslenme alışkanlıkları, sosyokültürel seviyesi, yaşamını geçirdiği coğrafi konumu ve tabi ki genetik mirası ile henüz bilinmeyen başka faktörlerin var olabileceği göz önünde bulundurulmalıdır. Çalışmamızın diğer kısıtılıkları tek merkezli ve hasta sayısının nispeten az olmasıdır. Ayrıca, her ne kadar gruplar ilk doğum yaşı dışında kaydedilen diğer değişkenler açısından benzer olsa da bulguların analizinde karıştırıcı faktörlerin etkisinin kontrol edildiği çok değişkenli istatistiksel yöntem kullanılmaması, adölesan gebeliklerin postmenopozal dönemdeki KMD üzerindeki etkisini tam olarak değerlendirilmesini engellemiştir.

\section{Sonuç}

Sonuç olarak, literatürde adölesan gebeliğin KMD ve kemik kütlesi üzerine olan etkisine dair görüş birliği mevcut değildir. Çalışma sonuçlarının birbirinden farklı oluşu, bu çalışmaların örneklemlerinin birçok ırktan, farklı özellikteki hasta popülasyonlarını ve kontrol gruplarını içermesinden kaynaklanmış olabileceğini düşündürmektedir. Çalışmamızda gruplar arasında KMD'de ölçülen Lomber T, Lomber Z, Femur $T$, Femur $Z$ düzeyleri arasında istatistiksel olarak anlamlı fark saptanmış olup, adölesan gebeliğin kemik mineral dansitometrisini pozitif yönde etkileyebileceği düşünülmüştür. $\mathrm{Bu}$ durumun gebelik sırasındaki artan osteoblastik aktiviteye bağlı kemik kütlesinde artışa neden olduğu ve adölesan gebeliklerin doruk kemik kitlesi üzerinde pozitif etkili olduğu hipoteziyle uyumludur. Her ne kadar çalışmamızda adölesan dönemdeki ilk doğumun artmış postmenopozal kemik yoğunluğu ile ilişkili olduğu gözlenmiş olsa da, ülkemizde halen çok önemli bir sorun olan ve kısa ve uzun dönemde birçok olumsuz maternal ve neonatal sonuçları olabileceği gösterilen adölesan dönemde yapılan doğumlarla ilişkili yanlış bir algı oluşturmak istememekteyiz. Ancak adölesan gebeliklerin postmenopozal kemik yoğunluğu üzerine etkisini değerlendirecek farklı yaş gruplarını da içeren geniş örneklemli ve daha kapsamlı çalışmalara ihtiyaç duyulmaktadır.

\section{Kaynaklar}

1. Dehne KL, Riedner G. Adolescence--a dynamic concept. Reprod Health Matters. 2001; 9 (17): 11-5.

2. Bryce J, Boschi-Pinto C, Shibuya K, Black RE; WHO Child Health Epidemiology Reference Group. WHO estimates of the causes of death in children. Lancet. 2005; 365 (9465): 1147-52.

3. Türkiye İstatistik Kurumu, İl, yaş grubu ve cinsiyete göre nüfus. 2017. [Cited 19 November 2018]. Available from http://www.tuik.gov.tr/PrelstatistikTablo.do?istab_id=945.

4. Hacettepe Üniversitesi Nüfus Etütleri Enstitüsü, Adölesan Doğurganlık ve Annelik. 2013 Türkiye Nüfus ve Sağlık Araştırması, Ankara, Türkiye, 2014. [Cited 19 November 2018]. Available from: http://www.hips.hacettepe.edu.tr/tnsa2013/rapor/TNSA_2013_ana_rapor.pdf

5. Lloyd T, Lin HM, Eggli DF, Dodson WC, Demers LM, Legro RS. Adolescent Caucasian mothers have reduced adult hip bone density. Fertil Steril. 2002; 77 (1): 136-40.

6. Ott SM, Scholes D, LaCroix AZ, Ichikawa LE, Yoshida CK, Barlow WE. Effects of contraceptive use on bone biochemical markers in young women. J Clin Endocrinol Metab. 2001; 86 (1): 179-85. 
7. Loro ML, Sayre J, Roe TF, Goran MI, Kaufman FR, Gilsanz V. Early identification of children predisposed to low peak bone mass and osteoporosis later in life. J Clin Endocrinol Metab. 2000; 85 (10): 3908-18.

8. Cho GJ, Shin JH, Yi KW, et al. Adolescent pregnancy is associated with osteoporosis in postmenopausal women. Menopause. 2012; 19 (4): 456-60.

9. Teerapornpuntakit J, Chanprapaph P, Charoenphandhu N. Previous Adolescent Pregnancy and Breastfeeding Does Not Negatively Affect Bone Mineral Density at the Age of Peak Bone Mass. Breastfeed Med. 2018; 13 (7): 500-5.

10. Yüce $T$, Kalafat E, Koc A. Adolescent pregnancy; a determinant of bone mineral density in peri-menopausal women? Maturitas. 2015; 82 (2): 203-7.

11. Kovacs CS. Maternal Mineral and Bone Metabolism During Pregnancy, Lactation, and Post-Weaning Recovery. Physiol Rev. 2016; 96 (2): 449-547.

12. Chan GM, McMurry M, Westover K, Engelbert-Fenton K, Thomas MR. Effects of increased dietary calcium intake upon the calcium and bone mineral status of lactating adolescent and adult women. Am $\mathrm{J}$ Clin Nutr. 1987; 46 (2): 319-23.

13. Bezerra FF, Mendonça LM, Lobato EC, O'Brien KO, Donangelo CM. Bone mass is recovered from lactation to postweaning in adolescent mothers with low calcium intakes. Am J Clin Nutr. 2004 Nov; 80 (5): 1322-6.

14. Wongdee K, Krishnamra N, Charoenphandhu N. Endochondral bone growth, bone calcium accretion, and bone mineral density: how are they related? J Physiol Sci. 2012; 62 (4): 299-307.

15. Rizzoli R, Bonjour JP, Ferrari SL. Osteoporosis, genetics and hormones. J Mol Endocrinol. 2001; 26 (2): 79 94.

16. Eisman JA. Genetics of osteoporosis. Endocr Rev. 1999 Dec; 20 (6): 788-804.

17. Khosla S, Melton LJ 3rd, Atkinson EJ, O'Fallon WM, Klee GG, Riggs BL. Relationship of serum sex steroid levels and bone turnover markers with bone mineral density in men and women: a key role for bioavailable estrogen. J Clin Endocrinol Metab. 1998; 83 (7): 2266-74.

18. Özcan H, Oskay Ü. Menopoz döneminde semptom yönetiminde kanıta dayalı uygulamalar. Göztepe Tıp Dergisi, 2013. 28 (4): 157-63.

19. Ward KA, Adams JE, Roberts SA, Mughal Z, Seif MW. Postpartum bone status in teenage mothers assessed using peripheral quantitative computed tomography. J Clin Densitom. 2009; 12 (2): 219-23.

20. Demir B, Haberal A, Geyik $P$, et al. Identification of the risk factors for osteoporosis among postmenopausal women. Maturitas. 2008; 60 (3-4): 253-6.

21. Kim YM, Hyun NR, Shon HS, et al. Assessment of clinical risk factors to validate the probability of osteoporosis and subsequent fractures in Korean women. Calcif Tissue Int. 2008; 83 (6): 380-7. 